\title{
O valor princípio da fraternidade como fundamento jurídico na solução de conflitos sobre identidade de gênero
}

\author{
El valor principio de la fraternidad como fundamento jurídico en la \\ solución de conflictos sobre identidad de género \\ the value principle of fraternity as a legal basis for the solution of \\ conflicts on gender identity
}

\author{
Danielle Rodrigues Machado ${ }^{1}$ \\ Laryssa dos Santos Rodrigues ${ }^{2}$ \\ Laura Gonçalves Pereira ${ }^{3}$
}

\begin{abstract}
Resumo
Este trabalho trata da aplicação do Princípio da Fraternidade como fundamento legal na resolução de conflitos sobre identidade de gênero. Esse valor princípio pode ser utilizado como ferramenta de flexibilização para solucionar conflitos. Dito isso, a interpretação das normas não pode ser estritamente positiva, devendo sempre ser levado em conta o caso concreto e seu contexto, a fim de atender as necessidades dos envolvidos da melhor forma, principalmente às minorias e, nesse caso específico, os conflitos relacionados com identidade de gênero, que vêm tomando cada vez mais lugar no cenário social e jurídico. Para acompanhar essa mudança, torna-se essencial uma nova interpretação da lei posta adaptando-se aos novos conceitos da contemporaneidade.
\end{abstract}

Palavras-Chave: Identidade de Gênero; Princípio da Fraternidade; Resolução de Conflitos.

\section{Resumen}

Este trabajo trata de la aplicación del Principio de la Fraternidad como fundamento legal en la resolución de conflictos sobre identidad de género. Este valor principio puede ser utilizado como herramienta de flexibilización para solucionar conflictos. Dicho esto, la interpretación de las normas no puede ser estrictamente positiva, debiendo siempre tenerse en cuenta el caso concreto y su contexto, a fin de atender a las necesidades de los involucrados de la mejor forma, principalmente a las minorías y, en ese caso específico, los conflictos relacionados con identidad de género, que vienen tomando cada vez más lugar en el escenario social y jurídico. Para acompañar ese cambio, se vuelve esencial una nueva interpretación de la ley puesta adaptándose a los nuevos conceptos de la contemporaneidad.

Palabras claves: Identidad de género; Principio de la fraternidad; Resolución de conflictos.

\section{Abstract}

This paper deals with the application of the Fraternity Principle as a legal basis in resolving conflicts about gender identity. This principle value can be used as a flexibilization tool to solve conflicts. That said, the interpretation of the rules can not be strictly positive, and the concrete case and context must always be taken into account in order to meet the needs of those involved, especially to minorities and, in this specific case,

\footnotetext{
${ }^{1}$ Graduando em Direito; Universidade Federal do Pampa - UNIPAMPA; Santana do Livramento, Rio Grande do Sul, Brasil; rdrgs.dnll@gmail.com

${ }^{2}$ Graduando em Direito; Universidade Federal do Pampa - UNIPAMPA; Santana do Livramento, Rio Grande do Sul, Brasil; laryssa.srodrigues12@gmail.com

${ }^{3}$ Graduando em Direito; Universidade Federal do Pampa - UNIPAMPA; Santana do Livramento, Rio Grande do Sul, Brasil; lauragpereira00@gmail.com
} 
related conflicts about gender identity, that have been taking more space in the social and legal scenario. To accompany this change, a new interpretation of the law is essential, adapting itself to the new concepts of contemporaneity.

Keywords: Conflict resolution; Gender identity; Principle of fraternity.

\section{Introdução}

Esse trabalho tem por finalidade, investigar de que modo o valor princípio da fraternidade pode ser utilizado como forma de flexibilização da lei positiva, visando sempre assegurar a efetivação dos direitos fundamentais de cada cidadão brasileiro, independentemente de sua identidade de gênero. Para isso, serão abordados conceitos referentes à identidade de gênero, à fraternidade e também, analisaremos jurisprudências relativas ao tema.

Pretende-se estudar uma forma alternativa para solucionar os conflitos ligados à identidade de gênero que, muitas vezes, não possuem respaldo na legislação, tornando possível resguardar os direitos fundamentais em questão, através do princípio da fraternidade.

Ambos conceitos são relativamente novos para o mundo jurídico, por isso, iremos falar sobre a identidade de gênero e o valor princípio da fraternidade em capítulos distintos, além de verificar a eficiência da hipótese levantada no último capítulo. Trata-se de uma abordagem extremamente relevante, pois buscamos uma nova possibilidade para resolver esses conflitos.

Para tal, utilizaremos o método dedutivo na investigação sobre como o princípio da fraternidade é aplicado em casos referentes à identidade de gênero, de forma a assegurar os direitos fundamentais dos envolvidos em cada caso concreto. Em primeiro momento, abordaremos o conceito de identidade de gênero, posteriormente, discutiremos o que é a fraternidade e como é vista no mundo do direito e por fim, analisaremos as jurisprudências correspondentes à temática do trabalho.

\section{Identidade de Gênero como Direito Humano}

O conceito de identidade de gênero é, muitas vezes, confundido com a definição de orientação sexual, por isso torna-se necessário a distinção entre o conceito de "gênero" e "sexo". Primeiramente o "sexo" inclui a ideia de diferenças biológicas de homens e mulheres, já o "gênero" extrapola o aspecto biológico e engloba também a concepção social da diferença entre os gêneros. De acordo com Clarindo Epaminondas de Sá Neto: 
A identidade de Gênero é independente do sexo, um ser humano pode ter a identidade de gênero de mulher, de homem ou ainda outras identidades de gênero possíveis. A identidade de gênero é uma construção social, e não um signo físico ou biológico. Trata-se da maneira como cada sujeito se auto identifica, seja como pertencente aos gêneros binários ou a nenhum deles. (NETO, 2017, p. 16)

Assim, o conceito do que é ser homem ou mulher não está ligado apenas a aceitação genital, mas sim a autocompreensão de cada pessoa e a forma como essa se expressa socialmente. Desta maneira, é possível entender que a concepção de identidade de gênero pode não ser compatível com o sexo designado no nascimento, pois a identidade de gênero é uma construção que expõe-se à mudanças que podem ocorrer durante o desenvolvimento dos indivíduos. Essa identidade relaciona-se à vivência de gênero de cada pessoa individualmente e internamente, vivida de forma íntima e profunda, que não necessariamente faz referência ao sexo concebido ao nascer. Inclui também as expressões de cada gênero, como a maneira de se vestir, falar e alguns gestos.

Dentre a divisão dos tipos de identidade de gênero encontram-se três classes fundamentais: os cisgêneros, não-binários e transgêneros. $O$ cisgênero refere-se a pessoa que não identifica-se com o gênero concedido a ela ao nascer. Já o indivíduo transgênero é aquele que não se auto identifica com o gênero que lhe foi biologicamente destinado ao nascer, identificando-se socialmente e psicologicamente com o outro gênero. O indivíduo não-binário se caracteriza com a fusão do feminino e do masculino ou a completa indiferença entre eles. As pessoas classificadas como não-binários excedem as funções que são destinadas socialmente a cada gênero e geram uma terceira identidade de gênero excedendo a barreira do paradigma "homem-mulher".

Grande parte das pessoas classificadas legalmente como mulher ou como homem possuirão sua identidade de gênero masculina ou feminina. Porém, é válido destacar que as pessoas transgêneros não se identificam com o gênero a elas atribuído e poderão desejar modificar seu estatuto físico, social e principalmente legal, para que desta maneira possam obter harmonia junto a sua identidade de gênero. Mudanças de aparência física e/ou exibição corporal por meio de intervenções médicas, tratamentos, cirúrgicas, vestimenta ou outros modos, possuem grande influência na experiência pessoal dos transgêneros.

Para acompanhar essa mudança, torna-se essencial uma nova interpretação da lei posta, adaptando-se aos novos contextos da contemporaneidade. A noção de gênero e as formas de sua expressão utilizadas na vida cotidiana, são peças fundamentais para o entendimento dos problemas dos direitos humanos que as pessoas transgêneros enfrentam. A Declaração Universal dos Direitos Humanos, que descreve os direitos humanos básicos, foi 
criada pela Organização das Nações Unidas (ONU) em 1948. Essa declaração foi adotada, com o intuito de combater intolerâncias, injustiças e desigualdades. Esses direitos são inegociáveis e universais, assim devendo ser respeitados por todas as nações. Essa Declaração possui como base na sua criação os princípios de liberdade e igualdade que garantem esses direitos a todos os seres humanos independentemente de raça, sexo, nacionalidade, etnia, idioma, religião ou qualquer outro aspecto. Desse modo é necessária a reflexão sobre a qualidade do exercício desses direitos exercida pelas diversas identidades de gênero. Existem várias ferramentas que podem ser utilizadas para a resolução de problemas relacionados a identidade de gênero, dentre elas está o princípio da fraternidade. Na visão de Marco Aquini, a fraternidade é um valor jurídico fundamental.

A fraternidade compromete o homem a agir de forma que não haja cisão entre os seus direitos e os seus deveres, capacitando-o a promover soluções de efetivação de Direitos Fundamentais de forma que, não, necessariamente, dependam, todas, da ação da autoridade pública, seja ela local, nacional ou internacional. (AQUINI, 2008, p. 138/139)

A fraternidade é um compromisso de todo cidadão atuante em uma sociedade livre e plural para a efetivação da liberdade e, principalmente, da igualdade como um todo. Esse valor princípio pode ser utilizado como ferramenta de flexibilização para solucionar conflitos. Dito isso, a análise das normas não pode ser realizada apenas de maneira positiva, sendo necessária a interpretação não apenas do caso concreto levando em consideração também o seu contexto, com o objetivo de compreender as necessidades dos envolvidos do melhor modo possível, essencialmente às minorias sociais e nesse caso especificamente aos conflitos referentes a identidade de gênero que vêm tomando cada vez mais lugar no cenário social e jurídico.

\section{A redescoberta da Fraternidade}

Mesmo tratando-se de uma discussão recente, a fraternidade, assim como a liberdade e a igualdade, tem seu marco inicial na Revolução Francesa, ocorrida no século XVIII, entretanto, caiu no esquecimento quando a sociedade lutou pelas mesmas. Em concordância à afirmação do ministro do Supremo Tribunal Federal (STF), Luiz Edson Fachin:

A contemporaneidade chamou ao palco mais diretamente a liberdade e a igualdade, alçadas em diversas Constituições como alicerces de estruturação dos Estados e dos valores da sociedade; fez-se uma ponte entre a liberdade e os direitos fundamentais, especialmente civis e políticos, e a igualdade e os direitos sociais e econômicos. Em segundo plano, nessa normatividade, teria ficado a fraternidade. (FACHIN, 2017, p. 12). 
A temática vem sendo debatida ao longo dos anos no Brasil, principalmente, dentro do universo jurídico, em congressos, conferências e encontros, com a finalidade de debater, especificamente, sobre o princípio da fraternidade. Tendo como exemplo, a Conferência do STF de Fraternidade e Humanismo, o IV Congresso Nacional de Direito e Fraternidade e I Congresso do Instituto Brasileiro de Educação em Direitos e Fraternidade.

Porém, quando falamos sobre fraternidade, é imprescindível citar Chiara Lubich, pois ela foi responsável pela "redescoberta" e difusão do tema, através da fundação do Movimento dos Focolares na Itália, em 1943, a fim de promover um mundo unido e mais fraterno. Dentro do viés político e religioso de Chiara, a fraternidade é alcançada por intermédio de um "amor especial", partindo cada indivíduo com seu próximo. Em outras palavras, a base da fraternidade é considerar todos como irmãos, ademais, está relacionada com solidariedade, empatia e amor, ainda que não represente estritamente o mesmo significado desses, mas sim, uma união entre eles, tornando-se um conceito bastante amplo e fácil de ser analisado em diversas esferas.

\subsection{O princípio da fraternidade no mundo jurídico}

Partindo do viés jurídico, é possível encontrar a fraternidade descrita como um princípio no preâmbulo da Constituição Federal de 1988, onde versa “... a igualdade e a justiça como valores supremos de uma sociedade fraterna, pluralista e sem preconceitos, fundada na harmonia social e comprometida, na ordem interna e internacional, com a solução pacífica das controvérsias ...", além de inúmeros incisos dessa lei maior.

O princípio é utilizado, em grande parte, para assegurar que os direitos fundamentais de cada cidadão sejam respeitados, pois é através da fraternidade que conquista-se uma sociedade livre, plural e igualitária, em concordância com o preâmbulo da Constituição, dependendo da preocupação do Estado em apoiar aqueles que necessitam, também, da concretização do respeito, por parte de cada indivíduo, aos direitos dos demais e o cumprimento de seus deveres. Conforme aponta a $\mathrm{Dr}^{\mathrm{a}}$ Olga Maria Boschi Aguiar de Oliveira:

[...] o princípio da fraternidade é entendido a partir de uma dimensão jurídica e relacional para ser vivenciado com responsabilidade, um dever do cidadão para com outro cidadão, do cidadão para com a comunidade, com a participação do Estado, ou seja, um compromisso de todas as pessoas humanas - e instituições públicas e privadas - que atuam em uma sociedade livre e plural para com o desenvolvimento e concretização da liberdade e da igualdade nos seus mais variados aspectos (jurídicos, políticos, econômicos, sociais, culturais, dentre outros), para a promoção e adesão do conjunto de seus membros para com os projetos de felicidade e bem estar comum da comunidade (nacional, internacional, global), como forma de superação do discurso liberal e individualista caracterizado pelos egoísmos particulares que impedem na prática uma convivência voltada para o outro, para o nosso, para o coletivo, resultando no desrespeito a dignidade de todos os seres 
humanos, principalmente, quando este está pautado nas relações de gênero. (OLIVEIRA, 2016, p. 12)

Após a exposição sobre o conceito e o surgimento histórico do Princípio da Fraternidade, discorreremos sobre as jurisprudências no próximo capítulo.

\section{Jurisprudências}

Diante do que já foi exposto, nosso ordenamento jurídico está intimamente ligado com o Princípio da Fraternidade. No que tange a identidade de gênero, é facilmente possível fazer uma relação entre isso, visto que essa relação está presente na sociedade diretamente. Um exemplo a ser citado é a questão da dignidade humana, onde se busca a compreensão de cada ser humano com sua própria identidade, não com a finalidade alheia ou metas coletivas, mas sim para si mesmo, visando uma segurança jurídica da pessoa perante a sociedade e sua família.

Uma discussão atual é a que refere-se à mudança de nome de pessoas que não se identificam com seu gênero biológico. Esse debate tem por objetivo decidir se pessoas que não se submeteram a cirurgia de transgenitalização teriam ou não o direito de alterar seu nome de registro. Segundo o voto do Ministro do STJ, Luis Felipe Salomão, não existe a necessidade de se fazer a cirurgia para a alteração do nome, pois o que deve ser levado em conta é a realidade social do indivíduo, diminuindo a importância da realidade biológica.

Segundo o ministro: "Independentemente da realidade biológica, o registro civil deve retratar a identidade de gênero psicossocial da pessoa transexual, de quem não se pode exigir a cirurgia de transgenitalização para o gozo de um direito." (SALOMÃO, 2017)

Diante disso, além de defender que esse é um direito para qualquer cidadão que queira usufruí-lo, Luis Felipe Salomão ainda diz que se trata do princípio constitucional da promoção da dignidade da pessoa humana, onde é considerado como valor fundamental o respeito às diferenças.

Sob essa ótica, devem ser resguardados os direitos fundamentais das pessoas transexuais não operadas à identidade (tratamento social de acordo com sua identidade de gênero), à liberdade de desenvolvimento e de expressão da personalidade humana (sem indevida intromissão estatal), ao reconhecimento perante a lei (independentemente da realização de procedimentos médicos), à intimidade e à privacidade (proteção das escolhas de vida), à igualdade e à não discriminação (eliminação de desigualdades fáticas que venham a colocá-los em situação de inferioridade), à saúde (garantia do bem-estar biopsicofísico) e à felicidade (bem-estar geral). (SALOMÃO, 2017, p. 2)

Além disso, o ministro ainda leva em conta fatores como o financeiro, pois para muitos transexuais é inacessível a realização da cirurgia. Também casos onde é inviável do 
ponto de vista médico. Deixando claro que a mudança do nome no registro civil não pode ficar dependendo dessas condições que nem sempre são viáveis. Portanto, defende:

\begin{abstract}
Ademais, o chamado sexo jurídico (aquele constante no registro civil de nascimento, atribuído, na primeira infância, com base no aspecto morfológico, gonádico ou cromossômico) não pode olvidar o aspecto psicossocial defluente da identidade de gênero autodefinido por cada indivíduo, o qual, tendo em vista a ratio essendi dos registros públicos, é o critério que deve, na hipótese, reger as relações do indivíduo perante a sociedade. (SALOMÃO, 2017, p. 2)
\end{abstract}

Perante essa discussão, fica claro que o Princípio da Fraternidade é uma boa forma de mediação desse tipo de conflito, abordando e defendendo, além do respeito entre os indivíduos, o diálogo entre as partes conflitantes. Essa forma de democratização de conflitos faz com que o diálogo seja restabelecido entre os envolvidos de forma interna, mas também coloca o assunto em debate perante a sociedade. Sendo assim, aquele antigo sistema jurídico que fomentava os litígios acaba sendo substituído pela tentativa de resolução de conflitos através de meios alternativos, focando nas necessidades da pessoa humana e em seus desejos, conforme sua forma de auto identificação perante a sociedade.

\title{
5. Considerações Finais
}

Tendo em vista a vasta análise dos fatos em questão, é possível traçar um panorama nacional, através da interpretação do preâmbulo da Constituição, e, em larga escala, internacional, reconhecendo na Declaração dos Direitos Humanos também a busca pela igualdade e justiça independente de qualquer aspecto como, religião, sexo, nacionalidade, etnia, idioma e nesse caso em especial, sem nenhuma distinção em relação a identidade de gênero.

É possível perceber, também, o avanço e desenvolvimento que o valor princípio da fraternidade pode gerar na resolução de conflitos, já que esse garante os direitos fundamentais de cada cidadão, pois é por meio da fraternidade que se alcançará uma sociedade livre, plural e igualitária. Isso só será possível no momento em que a sociedade passar a entender as necessidades particulares de cada indivíduo e compreendendo que isso vai além de um desejo alheio e pessoal, mas sim ultrapassa tal esfera.

Diante da análise da jurisprudência e dos conceitos expostos no presente trabalho, é possível perceber um avanço na interpretação da questão de identidade de gênero na sociedade e principalmente nos tribunais brasileiros. Sendo assim, é possível identificar uma mutação social de grande relevância tanto para a dignidade humana, quanto para a busca efetiva do direito de todos, perante suas individualidades. 
Porém, diante do exposto, fica claro que esse avanço deve andar em conjunto com o Princípio da Fraternidade, mais especificamente em sua utilização na mediação de tais conflitos. Mesmo que o uso da norma positivada seja de suma importância, os princípios devem sempre estarem presentes diante do mundo jurídico, tornando flexível a forma de interpretação das leis e sua aplicação.

\section{Referências}

BEZERRA, Eudes Vitor; FRANCO, Fernanda Cristina de Oliveira. Direitos Humanos $e$ Efetividade: Fundamentação e Processos Participativos. 2017. Disponível em: <https://www.conpedi.org.br/publicacoes/27ixgmd9/9h4q89rm/Idt7IX29xn8C7G70.pdf>.

$\begin{array}{lllll}\text { Acesso } & \text { em: } & 01 & \text { dez. } & 2018 .\end{array}$

BRASIL. Superior Tribunal de Justiça. Recurso Especial n ${ }^{\circ}$ 1.626.739/ DF - Distrito Federal. Relator: Luis Felipe Salomão. Pesquisa de Jurisprudência, Acórdãos, 09 maio 2017. Disponível em:

https://ww2.stj.jus.br/processo/revista/documento/mediado/?componente=ATC\&sequencial= $74184067 \&$ num_registro $=201602455869 \&$ data $=20170801 \&$ tipo $=5 \&$ formato $=P D F>$. Acesso em: 04 dez. 2018.

DE JESUS, Jaqueline Gomes. Orientações sobre Identidade de Gênero: Conceitos e Termos: Guia técnico sobre pessoas transexuais, travestis e demais transgêneros, para formadores de opinião. 2. 2012. Disponível em: <http://www.diversidadesexual.com.br/wpcontent/uploads/2013/04/GÊNERO-CONCEITOS-E-TERMOS.pdf $>$. Acesso em: 02 dez. 2018.

FACHIN, Luiz Edson. De fraternidade falando. 2017. Disponível em: <https://juslaboris.tst.jus.br/bitstream/handle/20.500.12178/105528/2017_fachin_luiz_fraterni dade falando.pdf?sequence=1\&isAllowed=y $>$. Acesso em: 24 nov. 2018.

HAMMARBERG, Thomas. Direitos Humanos e Identidade de Gênero. 2011. Disponível em: <https://transrespect.org/wp-content/uploads/2015/08/Hberg-port.pdf>. Acesso em: 24 nov. 2018.

LUBICH, 2004. Chiara Lubich: A fraternidade se realiza somente com um amor especial. Encontro do Movimento Político pela Unidade. Berna, 2004. Disponível em: <https://vimeo.com/162498389>. Acesso em: 23 nov. 2018.

OLIVEIRA, Olga Maria Boschi Aguiar de. Mulheres e trabalho: desigualdades $e$ discriminações - o resgate do princípio da fraternidade como expressão da dignidade humana. RJ: Lúmen júris, 2016, p. 12. 
STJ, 2018. Professora Chiara Lubich é homenageada no último dia do IV Congresso Nacional de Direito e Fraternidade: Seção Notícias, 9 nov. 2018. Disponível em: $<$ http://www.stj.jus.br/sites/STJ/default/pt_BR/Comunica\%C3\%A7\%C3\%A3o/noticias/Not\% C3\%ADcias/Professora-Chiara-Lubich-\%C3\%A9-homenageada-no-\%C3\%BAltimo-dia-doIV-Congresso-Nacional-de-Direito-e-Fraternidade>. Acesso em: 20 nov. 2018. 